\title{
Risk of Chronic Myeloid and Acute Leukemia Mortality after Exposure to Ionizing Radiation among Workers at Four U.S. Nuclear Weapons Facilities and a Nuclear Naval Shipyard
}

\author{
Mary K. Schubauer-Berigan, ${ }^{a, 1}$ Robert D. Daniels, ${ }^{a}$ Donald A. Fleming, ${ }^{a}$ Andrea M. Markey, ${ }^{a}$ James R. Couch, ${ }^{b}$ \\ Steven H. Ahrenholz, ${ }^{a}$ Jenneh S. Burphy, ${ }^{a, 2}$ Jeri L. Anderson ${ }^{a}$ and Chih-Yu Tseng ${ }^{a}$ \\ ${ }^{a}$ National Institute for Occupational Safety and Health; Division of Surveillance, Hazard Evaluations, and Field Studies, Cincinnati, Ohio 45213; \\ and ${ }^{b}$ Westat, Inc., Cincinnati, Ohio 45213
}

Schubauer-Berigan, M. K., Daniels, R. D., Fleming, D. A., Markey, A. M., Couch, J. R., Ahrenholz, S. H., Burphy, J. S., Anderson, J. L. and Tseng, C-Y. Risk of Chronic Myeloid and Acute Leukemia Mortality after Exposure to Ionizing Radiation among Workers at Four U.S. Nuclear Weapons Facilities and a Nuclear Naval Shipyard. Radiat. Res. 167, 222-232 (2007).

A nested case-control study was conducted among workers at five U.S. nuclear facilities to evaluate leukemia mortality risk (excluding chronic lymphocytic) from ionizing radiation using worksite doses and adjusting for potential confounding. Conditional logistic regression was used to estimate the relative risk (RR) of exposed workers and the excess relative risk (ERR) per unit of radiation among 206 cases and 823 agematched controls. Adjusting for sex and benzene, the RR of leukemia for workers receiving more than $10 \mathrm{mSv}$ was higher compared to those receiving lower or no dose; however, the risk increase was attenuated in the highest dose group. The ERR per $10 \mathrm{mSv}$ was $1.44 \%(95 \% \mathrm{CI}:<-1.03 \%, 7.59 \%)$ but was higher for workers born after 1921 compared to workers born earlier or when excluding leukemias of uncertain type. Excluding the $7 \%$ who were high-dose workers $(>100 \mathrm{mSv})$, the sex- and benzene-adjusted ERR per $10 \mathrm{mSv}$ was $6.82 \%$ (95\% CI: $-2.87 \%, 24.1 \%)$. The results suggest that risks among these nuclear workers are comparable to those observed in high-dose populations, although no evidence was observed of a positive quadratic dose-response term in this study. This large study is among the first to jointly evaluate benzene and ionizing radiation risk. ๑ 2007 by Radiation Research Society

\section{INTRODUCTION}

Ionizing radiation has been known as a cause of most forms of leukemia for over 50 years (1), and quantitative models exist for the association between leukemia and external ionizing radiation [other than chronic lymphocytic

\footnotetext{
${ }^{1}$ Address for correspondence: NIOSH, DSHEFS, MS-R15, 5555 Ridge Ave, Cincinnati, OH 45213; e-mail: MSchubauer-Berigan@cdc.gov.

${ }^{2}$ Current address: Martin County Health Department, Stuart, FL 34994.
}

leukemia (CLL)], based primarily on studies of populations exposed to relatively high doses (2-4).

Nuclear worker studies have been recognized as potentially informative on risks associated with low-dose, lowdose-rate exposures (5), and recent studies of leukemia among workers in the UK (6) and U.S. $(7,8)$ have found elevations in risk associated with ionizing radiation at low doses. The most comprehensive recent nuclear worker study, the International Agency for Research on Cancer (IARC) 15-country study, estimated elevated leukemia risk among 196 leukemia cases (9); however, potential confounding from factors such as solvent exposure or tobacco use could not be explored in that large cohort study. (Workers with a potential for radiation exposure may also have been in jobs with potential solvent exposure, since the use of these substances for various applications was known to have occurred in the earlier years of site operations.) The IARC study also excluded workers exposed to neutrons or plutonium due to uncertainties in their dose estimation in a large cohort setting.

The present study was conducted within the context of a large case-control study of leukemia nested among cohorts of workers at four U.S. Department of Energy (DOE) sites and a nuclear naval shipyard. The purpose of the study is to identify and characterize the association between external exposure to ionizing radiation and risk of all forms of leukemia. The present analysis was conducted specifically to evaluate the association between external ionizing radiation and leukemia excluding CLL (hereafter, leukemia) while controlling for known and suspected sources of confounding, particularly workplace solvent exposure and smoking. Risks of CLL (a disease not found in high-dose studies to be associated with ionizing radiation and not covered by nuclear worker compensation programs worldwide) within the cohort are described elsewhere (Schubauer-Berigan et al., submitted to Occup. Environ. Med.). Given the infrequent opportunities to evaluate two potential occupational carcinogens simultaneously, estimating the joint effects of benzene and ionizing radiation is also of interest. 
TABLE 1

Characteristics of Six Component Cohorts of the Multisite Leukemia Case-Control Study

\begin{tabular}{|c|c|c|c|c|c|c|c|c|c|}
\hline Site & $\begin{array}{l}\text { Period of } \\
\text { employment } \\
\text { eligibility }\end{array}$ & $\begin{array}{c}\text { Median } \\
\text { year } \\
\text { of birth }\end{array}$ & $\begin{array}{l}\text { Year of last } \\
\text { follow-up }\end{array}$ & $\begin{array}{c}\text { Cohort } \\
\text { size }^{a}\end{array}$ & $\begin{array}{l}\text { Median } \\
\text { duration } \\
\text { employed } \\
\text { (years) }\end{array}$ & $\begin{array}{c}\text { Deceased } \\
\text { through } \\
\text { follow-up }\end{array}$ & $\begin{array}{l}\text { No. total } \\
\text { leukemia } \\
\text { cases }^{b}\end{array}$ & $\begin{array}{c}\text { No. } \\
\text { non-CLL } \\
\text { cases }^{b}\end{array}$ & $\begin{array}{c}\text { No. } \\
\text { matched } \\
\text { controls }^{b}\end{array}$ \\
\hline Hanford & 1944-1978 & 1928 & 1994 & 36,384 & 5.9 & $31 \%$ & 94 & 77 & 321 \\
\hline $\mathrm{ORNL}^{c}$ & 1944-1978 & 1929 & 1990 & 19,815 & 2.3 & $26 \%$ & 49 & 37 & 153 \\
\hline $\mathrm{SRS}^{c}$ & 1952-1974 & 1928 & 1994 & 12,886 & 6.8 & $31 \%$ & 44 & 33 & 134 \\
\hline $\mathrm{LANL}^{c}$ & $1943-1977^{d}$ & 1932 & 1990 & 12,179 & 6.7 & $14 \%$ & 23 & & \\
\hline Zia workers at LANL & $1946-1978^{d}$ & 1927 & 1990 & 5686 & 5.2 & $27 \%$ & 14 & $32^{e}$ & $107^{e}$ \\
\hline $\mathrm{PNS}^{c}$ & $1952-1977$ & 1926 & 1996 & 9662 & 23.8 & $38 \%$ & 33 & 27 & 108 \\
\hline Total cohort & - & - & - & 94,517 & & & 257 & 206 & 823 \\
\hline
\end{tabular}

${ }^{a}$ Number meeting cohort criteria of having been employed at least 30 days and monitored for external ionizing radiation.

${ }^{b}$ Assigned to site of longest employment.

c Abbrevations: ORNL (Oak Ridge National Laboratory), SRS (Savannah River Site), LANL (Los Alamos National Laboratory), PNS (Portsmouth Naval Shipyard), CLL (chronic lymphocytic leukemia).

${ }^{d}$ A small number of workers who began work after these dates were included if they otherwise met cohort criteria.

${ }^{e}$ Cases and controls for LANL and Zia workers are combined in these analyses.

\section{METHODS}

\section{Cohort Assembly}

This study was reviewed at inception and annually thereafter by the NIOSH Human Subjects Review Board (Protocol no. HSRB-96DSHEFS-10). The methods for assembling the combined cohort are described in detail elsewhere (Schubauer-Berigan et al., submitted). Briefly, U.S. cohorts were identified based on the availability of demographic and external radiation monitoring data, sufficient cohort size, and the lack of substantial exposure to internal radiation sources. Based on these criteria, six cohorts were identified: Hanford, the Savannah River Site (SRS), Oak Ridge National Laboratory (ORNL), Los Alamos National Laboratory (LANL) including the Zia company, and the Portsmouth Naval Shipyard (PNS). Base cohorts for each of these sites were developed from studies conducted by previous investigators [Hanford (10), ORNL (11), SRS (12), LANL (13), Zia, ${ }^{3}$ PNS (14)]. Workers were eligible if they worked at the site for at least 30 days and were ever monitored for exposure to external ionizing radiation. These cohorts consist primarily of "production" and maintenance workers affiliated with prime site contractors; most previous investigators explicitly excluded construction subcontractors. Two exceptions are the PNS cohort, which includes all civilian site workers, and the LANL cohort, which includes workers at the Zia company, an early site construction and maintenance subcontractor. Characteristics of the component cohorts are described in Table 1.

\section{Vital Status and Leukemia Case Ascertainment}

Most cohorts were followed by previous investigators through at least 1990 using a variety of ascertainment sources, including state death records, obituary searches, the Social Security Administration, credit bureau services and the National Death Index (after 1978). The Hanford and SRS cohorts were followed through only 1986 and PNS through 1977. For this study, follow-up was extended through 1994 for Hanford and SRS and through 1996 for PNS, using linkage to the National Death Index. Death certificates were obtained for each decedent identified at Hanford, SRS and PNS during this additional period and were coded to the 9th revision of the International Classification of Diseases. Non-CLL leukemia cases were identified using the relevant codes from ICD revisions (i.e., 204-208, excluding 204.1, 204.9 and 208.1 for both ICD-8

${ }^{3}$ G. A. Galke, E. R. Johnson, G. L. Tietjen, Mortality in an ethnically diverse radiation occupational cohort. Los Alamos, NM: Los Alamos National Laboratory: Unpublished report. 70 pp. 1992. Available by contacting lead author of this study. and ICD-9) and by reviewing each death certificate with an indeterminate leukemia subtype (e.g., ICD-6 and -7 codes 204.0, "lymphatic leukemia"). Information from medical records obtained from site facilities was also used to identify leukemia subtype. Because non-underlying causes of death were not available for the LANL and Zia cohorts, only underlying cause of death was used to identify cases. Information on quality control review of coding of death certificates obtained from previous investigators is described elsewhere (Schubauer-Berigan et al., submitted).

\section{Control Selection}

Four control subjects were selected for each case based on incidence density sampling using attained age as the time scale $(15,16)$. In this method, controls were matched to cases on age as follows: They were required to have been hired younger than the death age of the case, to have worked at least 30 days, and to have survived to an older age than the case. Cases were permitted to serve as controls for other cases (provided they met the above criteria), and resampling of controls was permitted. As a result of this selection, 12 controls were selected twice. However, cases were not permitted to serve as their own control. No matching was conducted on potential confounding factors other than attained age, since these were deemed unreliable at the cohort level or were thought to be likely non-confounders. Incidence density sampling from the risk set within a nested cohort is analytically advantageous, since the odds ratio estimates the relative hazard (i.e., rate ratio) that would be obtained in a full cohort study that adjusts for age (16). To preserve this attribute, exposures for each control were truncated at the date (the "cutoff date") of his or her reaching the age at death of the matched case, minus any lag being evaluated.

\section{Exposure Assessment}

\section{Radiological variables}

The primary exposure evaluated was external radiation dose to the hematopoietic bone marrow from high-energy photons, lower-energy photons (including photofluorographic $\mathrm{X}$ rays and $\mathrm{X}$ rays emitted from plutonium sources), tritium and neutrons for each worker's entire employment period. Doses received by study subjects at other nuclear facilities (e.g., the Idaho National Laboratory, two additional Oak Ridge facilities, Rocky Flats, Fernald) were also incorporated as available through databases obtained for other epidemiological studies. Recorded doses through the cutoff date were adjusted for measurement biases aris- 
ing from exposure to heterogeneous radiation fields, calibration methods, dosimeter design, dosimeter energy response, and geometry of the critical organ $\left[(17)\right.$ and an unpublished report $\left.{ }^{4}\right]$. Methods used to estimate individual external doses from $\gamma$ - and X-ray exposures below the detection limit are described elsewhere (17-19). Individual doses from work-related medical X-ray examinations were estimated using software developed by the Finnish Center for Radiation and Nuclear Safety (20), based on facility-specific information on X-ray examination frequencies, techniques and equipment specifications (21).

Potential systemic deposition (as estimated by urinary excretion) of plutonium and subsequent dose to the bone marrow were evaluated among workers at the four DOE sites. Information on available plutonium compounds, bioassay methods, sample collection frequencies, chemical extraction and recovery, counting techniques, reporting requirements, detection levels, and incidence or confirmation of plutonium deposition was used to develop thresholds for exposure categories. Internal dose for each case and control receiving positive plutonium deposition was assessed through the cutoff date, using methods described elsewhere (22).

Main analyses were conducted using equivalent dose to account for the potentially greater effectiveness of high-LET radiation. For neutron doses, radiation weighting factors were applied based on neutron energy using values from ICRP Publication 60 (23). A radiation weighting factor of 20 was applied for plutonium bone marrow dose. Bone marrow doses were lagged for most analyses by discounting any exposure received during the 2 years before the cases and controls reached the age at death of the case. Other dose lags were explored as well (described below).

\section{Benzene and carbon tetrachloride}

Details about exposure assessment for the potential leukemogens benzene and carbon tetrachloride are documented elsewhere (Fleming et al., submitted; Markey et al., submitted). Briefly, a job-exposure matrix (JEM) approach was used to link study subjects with benzene and carbon tetrachloride exposure activities. An algorithm was developed for the calculation of annual and cumulative exposure scores for both benzene and carbon tetrachloride for each study subject. Study subjects linked with an exposure activity were assigned to one of five worker categories based on work history and exposure activity history information. For each worker category within each exposure activity, values for exposure level, frequency and duration were estimated based on available information regarding the conduct of the activity at the site and professional judgment of the NIOSH industrial hygienists performing the exposure assessment (see the Appendix). Numerical values were assigned to qualitative exposure level estimates $(\mathrm{High}=1$, Medium $=0.5$, Low $=0.1$, Very Low $=0.01$, and Unexposed $=0$ ) to allow calculation of exposure scores for both benzene and carbon tetrachloride.

For both chemicals the definition for a "High" qualitative exposure level was an exposure level estimated at the current (2004) occupational limit prescribed by the American Conference of Governmental Industrial Hygienists (24). An exposure level of "Medium" is judged to be approximately half the occupational limit, and so on. Normalization of the exposure scores to their respective limits provided a basis for comparison of the exposure scores across all sites and periods in the study. For epidemiological analyses, solvent-exposed workers were classified into exposure score categories (and compared to unexposed workers) using a cut-point based on the median score among the exposed group (80 for carbon tetrachloride and 200 for benzene).

\section{Smoking status}

Methods for estimating smoking histories are described elsewhere (Schubauer-Berigan et al., submitted). Briefly, smoking information was

${ }^{4}$ J. J. Fix, R. I. Scherpelz, D. J. Strom and R. J. Traub, Dose validation for NIOSH/HERB multi-site leukemia case control study, PNWD-3538. Battelle Pacific Northwest Division, Richland, WA, 2005. Available by contacting lead author of this study. obtained from worksite medical records. Workers were classified as never-smokers, ex-smokers or current smokers. Current cigarette smokers were defined as workers who were smoking cigarettes as of their cutoff date or workers who quit smoking 5 or fewer years prior to their cutoff date. For the $54 \%$ of workers with insufficient smoking history information, smoking status was imputed based on the socioeconomic status associated with the first job title (25), refined to reflect average smoking histories for a given job from survey data collected in the 1950s to $1980 \mathrm{~s}$ (26). These assignments were validated using the relation between job titles and smoking history information for workers with complete information. The surrogate methods accurately identified $61 \%$ of the smokers and $64 \%$ of non-smokers.

\section{Statistical Analysis}

Descriptive statistics for the cohort and for case-control study subjects were calculated using SAS ver 8.0. Epidemiological analyses were conducted using conditional logistic regression [PECAN module of Epicure (27)]. In this analysis, mortality rate ratios are estimated using the odds ratio, which is calculated as a function of a series of parameters and variables of the following general form:

$$
\ln R R \approx \ln O R=\sum_{i=1}^{n} \beta_{i} x_{i}
$$

However, the model is analyzed conditionally on the stratum total (i.e., the matched risk sets). For most models, a linear excess relative risk (ERR) model was evaluated. This model, which is shown below, is commonly used to analyze radiological cohorts $(5,28)$ and facilitates comparisons to other studies.

$$
R R \approx 1+\sum_{i=1}^{n} \beta_{i} x_{i}
$$

Two-sided 95\% confidence intervals for $\beta_{i}$ parameters were estimated using profile likelihood methods (27). Wald-type 95\% confidence intervals were constructed for joint effects of benzene and radiation, based on a loglinear model.

\section{Modeling Approach}

The analysis approach was specified a priori. Potential confounders (including sex, race/ethnicity, facility of longest employment, smoking status, tertiles of birth cohort and hire year, and exposure to benzene and carbon tetrachloride) were incorporated if they changed the parameter estimate of risk from external radiation by more than $15 \%$ on a relative scale. Rate ratio modification was evaluated by a likelihood ratio test at a $P<0.05$ of the cross-product term for the interaction variable of the potential effect modifier with dose, evaluated against a $\chi^{2}$ distribution (27) with degrees of freedom equal to the number of interaction terms added. The main exposures considered were (1) external radiation bone marrow doses from all sources and (2) external and internal (plutonium) exposures, using ICRP 60 radiation weighting factors. The dose metric resulting in the smallest model deviance was employed in other analyses.

Sensitivity analyses were conducted of the selected baseline model by adjusting the following conditions: (1) excluding 22 cases of leukemia of unspecified cell type and/or chronicity; (2) excluding cases and controls with $100 \mathrm{mSv}$ or more cumulative dose, to evaluate the effects of exposures at low doses that are more relevant to current occupational settings; (3) evaluating the impact of using differing lags, including 0, 5, 7 and 10 years; (4) evaluating the time course of leukemia risk after exposure, by dividing the cumulative dose into the following time windows: $0-2$ years, $2-5$ years, $5-10$ years, $10-20$ years, and $\geq 20$ years before the cutoff date; (5) evaluating the non-linearity of the dose response by adding a quadratic term in dose. 
TABLE 2

Dose Characteristics of Non-CLL Leukemia Case and Control Groups

\begin{tabular}{lccc}
\hline & Characteristic & Cases & Controls \\
\hline & Total bone marrow dose $(\mathrm{mSv})$ & \\
Two-year lag: & mean, SE & $30.6,3.82$ & $24.9,2.04$ \\
& median & 10.5 & 7.34 \\
& Bone marrow external dose $(\mathrm{mSv})$ & \\
Two-year lag: & mean, SE & $29.2,3.76$ & $23.1,1.75$ \\
& median & 10.3 & 7.19 \\
No lag: & moton and tritium dose (mSv) \\
Two-year lag: & mean, SE & $29.3,3.75$ & $23.0,1.66$ \\
& median & 10.4 & 7.40 \\
Five-year lag: & mean, SE & $29.0,3.73$ & $22.6,1.64$ \\
& median & 10.3 & 7.16 \\
Ten-year lag: & mean, SE & $28.0,3.67$ & $21.9,1.62$ \\
& median & 9.73 & 6.98 \\
& mean, SE & $25.0,3.57$ & $20.1,1.55$ \\
& median & 8.30 & 6.30 \\
\hline
\end{tabular}

\section{RESULTS}

\section{Descriptive and Univariate Analyses}

The case-control group was predominantly non-Hispanic white $(93 \%)$ and male $(86 \%)$. Most $(64 \%)$ were born before 1922 , and $65 \%$ were hired before 1953 . Only $22 \%$ of study subjects were exposed to benzene and $24 \%$ to carbon tetrachloride. Most (64\%) were either current or ex-smokers as of the cutoff date. Photons and tritium comprised 91$95 \%$ of the total bone marrow dose for study subjects (Table 2). Mean and median cumulative bone marrow doses were higher among cases than controls, although confidence intervals overlapped (not shown).

Women had less than half the age-adjusted non-CLL leukemia (hereafter, leukemia) risk of men (Table 3). Compared to white workers, non-white or Hispanic workers had about half the mortality risk of leukemia. A slight decrease in leukemia risk by increasing birth cohort was observed. Workers hired later had slight but nonsignificant elevations in leukemia risk. Age-adjusted leukemia rates also varied little by employment facility, but workers at LANL experienced slightly higher rates than those at other facilities (Table 3).

Ex-smokers and current smokers had a slightly increased risk of leukemia compared to never-smokers (although confidence intervals overlapped unity). There was a slight trend in increasing leukemia risk with increasing benzene exposure score, and workers exposed to the highest benzene exposure scores had an $80 \%$ increase compared to the unexposed. Leukemia risk elevations of $20 \%$ were observed among those exposed to the highest carbon tetrachloride exposure scores, although the confidence intervals were wide (Table 3).
Risks Associated with Radiation Exposures: Main Analysis

Workers with excreted plutonium of greater than 1.7 $\mathrm{mBq}$ day $^{-1}$ showed slightly higher rates of leukemia than workers with no plutonium deposition, although confidence intervals overlapped unity (Table 4). Age-adjusted leukemia mortality rates were higher among workers receiving doses of more than $10 \mathrm{mSv}$ external dose compared to those receiving less than $1 \mathrm{mSv}$. The estimated ERR per $10 \mathrm{mSv}$ was $4.3 \%$ (95\% CI: $-0.29 \%, 13 \%$ ). Similar estimates (with a slightly lower deviance for comparable models) were observed when dose included the bone marrow contribution from plutonium (Table 4). Models based on the linear ERR had smaller deviance (e.g., 659.814 for total bone marrow dose) compared to loglinear models (e.g., 661.130).

Incorporation of sex alone into the risk models reduced risk estimates within each exposed category (Table 4) and reduced ERR per $10 \mathrm{mSv}$ estimates to $2.43 \%$ (95\% CI: $<-1.03 \%, 9.37 \%$ ), and incorporating benzene alone into the model reduced the risk estimates to $2.72 \%$ (95\% CI: $<-1.03 \%, 9.99 \%)$ per $10 \mathrm{mSv}$. Adjustment for both sex and benzene exposure reduced the risk estimates to $1.44 \%$ (95\% CI: $<-1.03 \%, 7.59 \%)$ per $10 \mathrm{mSv}$. In this model, the RR for females (compared to males) was 0.45 (95\% CI: $0.24,0.76)$. The RR for workers with $<200$ benzene score (compared to unexposed) was 1.20 (95\% CI: 0.74, 1.90) and for workers with $>200$ was 1.71 (95\% CI: 1.07, 2.70). Adjustments for race, hire year and smoking reduced risk estimates (and adjustments for facility and birth cohort increased risk estimates) by less than $15 \%$ on a relative scale (data not shown). Adjusting for benzene and sex, workers who received more than $10 \mathrm{mSv}$ of radiation had a relative risk of 1.45 (95\% CI: 1.04, 2.01) compared to workers receiving lower doses.

Strong rate ratio modification was observed for both birth cohort and hire year (Table 5), two variables that are highly correlated within this study group (Pearson $r=0.55,95 \%$ CI: $0.50,0.59)$. Risks per unit dose were higher for those born after 1921 compared to those born earlier and for those hired after 1952 compared to those hired earlier (Table 5). Weaker evidence of rate ratio modification by facility was observed, with positive risk estimates observed for ORNL, SRS and PNS, negative estimates for LANL, and estimates near zero for Hanford (Table 5). Rate ratio modification by facility, birth cohort and hire year was similar when adjusted for sex and benzene exposure (data not shown). For further analyses, just birth cohort was used to avoid overstratification.

\section{Risks Associated with Radiation Exposures: Sensitivity Analysis}

In analyses excluding the 22 leukemias of ambiguous type (Table 6), excess relative risks per unit dose were approximately $50-80 \%$ higher than comparable analyses including all leukemias. Adjusting for sex and benzene (the 
TABLE 3

Confounder-Related Characteristics of Non-CLL Leukemia Cases and Age-Matched Controls

\begin{tabular}{|c|c|c|c|c|}
\hline & Cases & Controls & Total & $\begin{array}{l}\text { Univariate rate } \\
\text { ratio }(95 \% \mathrm{CI})\end{array}$ \\
\hline Number & 206 & 823 & 1029 & \\
\hline Male & $191(93 \%)$ & $692(84 \%)$ & $883(86 \%)$ & 1.0 \\
\hline Female & $15(9 \%)$ & $131(16 \%)$ & $146(14 \%)$ & $0.42(0.23,0.71)$ \\
\hline White, non-Hispanic & $197(96 \%)$ & $756(92 \%)$ & $953(93 \%)$ & 1.0 \\
\hline Non-white or Hispanic & $9(4 \%)$ & $67(8 \%)$ & $76(7 \%)$ & $0.51(0.24,1.00)$ \\
\hline Birth year $<1912$ & $66(32 \%)$ & $247(30 \%)$ & $313(30 \%)$ & 1.0 \\
\hline Birth year 1912-1921 & $72(35 \%)$ & $276(34 \%)$ & $348(34 \%)$ & $0.93(0.62,1.42)$ \\
\hline Birth year >1921 & $68(33 \%)$ & $300(36 \%)$ & $368(36 \%)$ & $0.77(0.47,1.24)$ \\
\hline Hire year < 1947 & $67(33 \%)$ & $262(32 \%)$ & $329(32 \%)$ & 1.0 \\
\hline Hire year $1947-1952$ & $76(37 \%)$ & $269(33 \%)$ & $345(34 \%)$ & $1.11(0.76,1.62)$ \\
\hline Hire year $\geq 1953$ & $63(31 \%)$ & $292(35 \%)$ & $355(35 \%)$ & $1.34(0.55,3.27)$ \\
\hline Benzene $=0$ & $149(72 \%)$ & $657(80 \%)$ & $806(78 \%)$ & 1.0 \\
\hline $0<$ Benzene $<200$ & $26(13 \%)$ & $91(11 \%)$ & $117(11 \%)$ & $1.26(0.77,1.98)$ \\
\hline Benzene $\geq 200$ & $31(15 \%)$ & $75(9 \%)$ & $106(10 \%)$ & $1.82(1.14,2.85)$ \\
\hline $\mathrm{CCl}_{4}=0$ & $156(76 \%)$ & $631(77 \%)$ & $787(76 \%)$ & 1.0 \\
\hline $0<\mathrm{CCl}_{4}<80$ & $25(12 \%)$ & $108(13 \%)$ & $133(13 \%)$ & $0.94(0.58,1.48)$ \\
\hline $\mathrm{CCl}_{4} \geq 80$ & $25(12 \%)$ & $84(10 \%)$ & $109(11 \%)$ & $1.20(0.73,1.91)$ \\
\hline Benzene $+\mathrm{CCl}_{4}=0$ & $127(62 \%)$ & $542(66 \%)$ & $669(65 \%)$ & 1.0 \\
\hline $0<$ Benzene $+\mathrm{CCl}_{4}<200$ & $39(19 \%)$ & $160(19 \%)$ & $199(19 \%)$ & $1.05(0.69,1.54)$ \\
\hline Benzene $+\mathrm{CCl}_{4} \geq 200$ & $40(19 \%)$ & $121(15 \%)$ & $161(16 \%)$ & $1.41(0.93,2.11)$ \\
\hline Hanford & $77(37 \%)$ & $321(39 \%)$ & $398(39 \%)$ & 1.0 \\
\hline ORNL & $37(18 \%)$ & $153(19 \%)$ & $190(18 \%)$ & $1.01(0.64,1.55)$ \\
\hline LANL/Zia & $32(16 \%)$ & $107(13 \%)$ & $139(14 \%)$ & $1.25(0.78,1.98)$ \\
\hline SRS & $33(16 \%)$ & $134(16 \%)$ & $167(16 \%)$ & $1.03(0.65,1.61)$ \\
\hline PNS & $27(13 \%)$ & $108(13 \%)$ & $135(13 \%)$ & $1.05(0.63,1.68)$ \\
\hline Never-smokers & $65(32 \%)$ & $303(37 \%)$ & $368(36 \%)$ & 1.0 \\
\hline Ex-smokers ${ }^{a}$ & $79(38 \%)$ & $279(34 \%)$ & $358(35 \%)$ & $1.38(0.93,2.07)$ \\
\hline Current smokers & $62(30 \%)$ & $241(29 \%)$ & $303(29 \%)$ & $1.16(0.78,1.73)$ \\
\hline
\end{tabular}

${ }^{a}$ Last smoked at least 5 years before cutoff date.

only apparent confounders), the ERR per $10 \mathrm{mSv}$ was $2.60 \%(<-1.03 \%, 10.3 \%)$. Evidence exists for rate ratio modification by only birth cohort $(P=0.0004)$ and hire year $(P=0.004)$, in the same direction as for all leukemias (data not shown).

Excess relative risk estimates for leukemia related to total bone marrow dose increased with the exclusion of workers (including 19 cases) receiving $100 \mathrm{mSv}$ or more total dose (Table 7). Incorporation of sex and benzene exposure decreased ERR estimates by $31 \%$ and $16 \%$, respectively, when excluding high-dose workers; the incorporation of no other risk factor changed risk coefficients by more than $11 \%$. The ERR estimate per $10 \mathrm{mSv}$ was $6.82 \%$ (95\% CI: $-2.87 \%, 24.1 \%$ ), after adjusting for sex (RR females/ males: $0.41 ; 95 \%$ CI: $0.22,0.72$ ) and benzene exposure (RR $<200$ /unexposed: 1.27 ; 95\% CI: 0.76, 2.07; and RR $\geq 200 /$ unexposed: 1.38 ; $95 \%$ CI: $0.80,2.31$ ). No evidence of radiation rate ratio modification was observed by sex $(P=$ $0.08)$, race $(P=0.61)$, birth cohort $(P=0.20)$, hire year $(P=0.29)$, smoking $(P=0.36)$, facility $(P=0.36)$, or benzene exposure $(P=0.42)$. Removing just workers (including 16 cases) who received $100 \mathrm{mGy}$ or more of photon dose resulted in an ERR per $10 \mathrm{mSv}$ of $7.61 \%$ (95\% CI:
$-1.57,23.7 \%$ ), when adjusting for sex and benzene exposure.

Excluding plutonium bone marrow dose had little effect on leukemia risk estimates (Table 4). After adjusting for sex, relative risks were very similar, although relative risks at each dose category level were slightly lower when just external dose was included. Similarly, removing neutron dose had little effect on estimated risks (data not shown).

Comparison of different dose lags showed that a lag of 2 years yielded the lowest deviance for a model including all workers and adjusting for sex (Table 8). Considering just those born after 1921, the lowest deviance was associated with a 7-year lag (although deviance was similar with a lag of zero). Splitting radiation dose into periods ("windows") in years prior to the cutoff date resulted in positive estimates for exposures between 5 and 20 years for analyses including all workers (Table 9). This pattern was also similar to those for workers in the two earlier birth cohorts. For workers born after 1921, ERR per unit dose was positive for all periods except the 2-5-year window and tended to decrease with increasing time after exposure. For workers hired after 1952, the lowest deviance was associated with a 2-year lag, and time windows for exposure 
TABLE 4

Dosimetry-Related Characteristics and Risk of Non-CLL Leukemia

\begin{tabular}{|c|c|c|c|c|c|}
\hline Characteristic & Cases & Controls & Total & \multicolumn{2}{|c|}{ Odds ratio $(95 \% \mathrm{CI})$} \\
\hline Plutonium excreta level $(x)$ categories: & & & & \multicolumn{2}{|l|}{ Unadjusted $^{a}$} \\
\hline Unmonitored & $112(58 \%)$ & $474(54 \%)$ & $586(57 \%)$ & \multicolumn{2}{|l|}{1.0} \\
\hline Monitored, with $x<1.7 \mathrm{mBq}$ day $^{-1}$ & $70(34 \%)$ & $282(37 \%)$ & $352(34 \%)$ & \multicolumn{2}{|l|}{$1.05(0.75,1.47)$} \\
\hline $1.7 \mathrm{mBq}$ day $^{-1} \leq x<17 \mathrm{mBq}$ day $^{-1}$ & $16(5 \%)$ & $43(6 \%)$ & $59(6 \%)$ & \multicolumn{2}{|l|}{$1.57(0.84,2.83)$} \\
\hline$x \geq 17 \mathrm{mBq}$ day $^{-1}$ & $8(3 \%)$ & $24(3 \%)$ & $32(3 \%)$ & \multicolumn{2}{|l|}{$1.42(0.59,3.11)$} \\
\hline \multicolumn{4}{|l|}{ Bone marrow external dose: } & Unadjusted $^{a}$ & Adjusted for sex ${ }^{a}$ \\
\hline \multirow{7}{*}{$\begin{aligned} \text { Two-year lag: } & 0-<1 \mathrm{mSv} \\
& 1-<10 \mathrm{mSv} \\
& 10-<50 \mathrm{mSv} \\
& 50-<100 \mathrm{mSv} \\
& \geq 100 \mathrm{mSv}\end{aligned}$} & $28(14 \%)$ & $141(17 \%)$ & $169(16 \%)$ & 1.0 & 1.0 \\
\hline & $72(35 \%)$ & $356(43 \%)$ & $428(42 \%)$ & $1.04(0.65,1.71)$ & $0.98(0.61,1.62)$ \\
\hline & $73(35 \%)$ & $232(28 \%)$ & $305(30 \%)$ & $1.68(1.03,2.80)$ & $1.46(0.89,2.46)$ \\
\hline & $17(8 \%)$ & $49(6 \%)$ & $66(6 \%)$ & $1.80(0.89,3.56)$ & $1.59(0.78,3.18)$ \\
\hline & $16(7 \%)$ & $45(5 \%)$ & $61(6 \%)$ & $1.92(0.92,3.95)$ & $1.61(0.76,3.34)$ \\
\hline & \multirow{2}{*}{\multicolumn{3}{|c|}{$\begin{array}{l}\text { Model deviance (free parameters): } \\
\text { ERR per } 10 \mathrm{mSv}(95 \% \mathrm{CI})\end{array}$}} & $652.279(4)$ & $644.748(5)$ \\
\hline & & & & \multicolumn{2}{|l|}{$0.043(-0.0029,0.13)$} \\
\hline \multirow{2}{*}{\multicolumn{4}{|c|}{$\begin{array}{l}\text { Total bone marrow dose (including } \\
\text { plutonium): }\end{array}$}} & \multicolumn{2}{|c|}{ Odds ratio $(95 \% \mathrm{CI})$} \\
\hline & & & & Unadjusted $^{a}$ & Adjusted for $\operatorname{sex}^{a}$ \\
\hline \multirow{7}{*}{$\begin{aligned} \text { Two-year lag: } & 0-<1 \mathrm{mSv} \\
& 1-<10 \mathrm{mSv} \\
& 10-<50 \mathrm{mSv} \\
& 50-<100 \mathrm{mSv} \\
& \geq 100 \mathrm{mSv}\end{aligned}$} & $28(14 \%)$ & $141(17 \%)$ & $169(16 \%)$ & 1.0 & 1.0 \\
\hline & $71(34 \%)$ & $350(43 \%)$ & $421(41 \%)$ & $1.05(0.65,1.72)$ & $0.98(0.61,1.63)$ \\
\hline & $70(34 \%)$ & $232(28 \%)$ & $302(29 \%)$ & $1.61(0.98,2.70)$ & $1.41(0.85,2.38)$ \\
\hline & $18(9 \%)$ & $50(6 \%)$ & $68(7 \%)$ & $1.89(0.94,3.72)$ & $1.65(0.82,3.28)$ \\
\hline & $19(9 \%)$ & $50(6 \%)$ & $69(6 \%)$ & $2.05(1.02,2.62)$ & $1.74(0.85,3.51)$ \\
\hline & \multirow{2}{*}{\multicolumn{3}{|c|}{$\begin{array}{l}\text { Model deviance (free parameters): } \\
\text { ERR per } 10 \mathrm{mSv}(95 \% \mathrm{CI})\end{array}$}} & $652.123(4)$ & $644.575(5)$ \\
\hline & & & & $0.040(-0.0047,0.12)$ & $0.024(-0.010,0.094)$ \\
\hline
\end{tabular}

${ }^{a}$ All analyses are adjusted for attained age as a result of incidence-density sampling.

of 2-5 years were associated with highest radiation-associated risk (data not shown).

There was no evidence of upward curvature of risk at high doses. The addition of a quadratic term for dose with sex in the model did not improve model fit when all workers were considered (likelihood ratio statistic $=1.89$ with $1 d f, P=0.158$ ), and the estimated quadratic coefficient was negative. Results were similar when benzene was also incorporated.

Although not part of the original analysis plan, models incorporating the log of dose and (separately) trimmed by the top $1 \%$ of the entire dose distribution [to reduce sensitivity to outliers (29)] was evaluated. The trimmed ERR per $10 \mathrm{mSv}$, adjusting for sex and benzene, was $2.45 \%$ (95\% CI: $-1.89 \%, 10.4 \%$ ), and the resulting curves for both models are shown in Fig. 1.

\section{DISCUSSION}

This study found the relative risk of leukemia among workers receiving work-related bone marrow doses $(\gamma$ and $\mathrm{X}$ rays from plutonium and work-related medical sources, tritium, neutrons and plutonium) of more than $10 \mathrm{mSv}$ was significantly higher than for workers receiving lower doses. Quantitative dose-response analyses estimated statistically nonsignificant positive risk per unit dose, which showed evidence of modification by birth cohort and hire year. Estimated risk per unit dose varied when excluding leukemias of uncertain type, increasing from $1.44 \%$ (95\% CI:
$<-1.03 \%, 7.59 \%)$ to $2.60 \%(<-1.03 \%, 10.3 \%)$ per 10 $\mathrm{mSv}$. At the mean cumulative dose among cases of about $30 \mathrm{mSv}$ (including neutron doses with a radiation weighting factor of approximately 10 and plutonium with a weighting factor of 20), the ERR estimate using the latter estimate is $7.8 \%(<-3.09 \%, 30.9 \%)$.

Risk estimates for non-CLL leukemia in the 15-country IARC study (9) were $1.89 \%(<0,8.47 \%)$ per $10 \mathrm{mSv}$, similar to those observed here. These two studies are not independent: Hanford and ORNL were included in both. However, the cohort inclusion criteria were different for the two studies, and this study included 8 years of additional follow-up for Hanford. Thus only 47 of the leukemia deaths (23\% of the total in this study and $24 \%$ in the IARC study) overlapped. The detailed dosimetry permissible within a case-control setting allowed the estimation of bone marrow doses from all workplace sources, including photons, tritium, neutrons and plutonium. This study also adjusted for exposure to benzene, which was not feasible in the 15country study. Recent estimates of radiation-associated risk within the PNS cohort $(8,25)$ are somewhat higher than those observed in this study but are consistent with the rate ratio modification by facility shown in Table 5 .

Comparison of the risks per unit dose estimated here to results from studies of atomic bomb survivors [men age 20-60 at exposure, $n=83$ (9)] shows good similarity: Estimates within the linear region (using a linear-quadratic model) of the A-bomb studies are 1.54\% (95\% CI: $-1.14 \%$ to $5.33 \%$ ) per $10 \mathrm{mGy}$, and estimates based on a purely 
TABLE 5

Tests of Bone Marrow Radiation Dose Effect Modification by Sex, Race, Facility, Birth Cohort, Hire Year, and Benzene Exposure in a Linear Excess Relative Risk (ERR)

Model

\begin{tabular}{|c|c|c|}
\hline Model & $\begin{array}{l}\mathrm{ERR} \cdot 10 \mathrm{mSv}^{-1} \\
\quad 95 \% \mathrm{CI}\end{array}$ & $\begin{array}{l}\text { Likelihood ratio } \\
\text { statistic for } \\
\text { interaction, } d f, P\end{array}$ \\
\hline $\begin{array}{l}\text { Sex: Males } \\
\text { Females }\end{array}$ & $\begin{array}{l}0.0219(<-0.0102,0.0907) \\
0.110(-0.0732,0.125)\end{array}$ & $0.6069,1, P>0.5$ \\
\hline $\begin{array}{l}\text { Race: non-Hispanic white } \\
\text { Non-white or Hispanic }\end{array}$ & $\begin{array}{l}0.0354(-0.0067,0.113) \\
0.191(<0.0120,1.86)\end{array}$ & $0.5004,1, P=0.48$ \\
\hline $\begin{array}{l}\text { Birth cohort: }<1912 \\
\quad 1912-1921 \\
>1921\end{array}$ & $\begin{array}{l}-0.0103\left(\mathrm{NC},{ }^{a} \mathrm{NC}\right) \\
-0.0015(<-0.0252,0.0804) \\
0.370(0.118,1.08)\end{array}$ & $15.62,2, P=0.0004$ \\
\hline $\begin{array}{l}\text { Hire year: <1947 } \\
\quad 1947-1952 \\
>1952\end{array}$ & $\begin{array}{l}-0.0104(\mathrm{NC}, \mathrm{NC}) \\
0.0257(-0.0159,0.136) \\
0.277(0.068,0.810)\end{array}$ & $10.25,2, P=0.006$ \\
\hline $\begin{array}{l}\text { Facility: Hanford } \\
\text { ORNL } \\
\text { LANL/Zia } \\
\text { SRS } \\
\text { PNS }\end{array}$ & $\begin{array}{l}0.00542(-0.0211,0.0880) \\
0.0567(<-0.0269,0.417) \\
-0.0104(\mathrm{NC}, \mathrm{NC}) \\
0.306(0.0477,>1.30) \\
0.428(0.0292,>0.453)\end{array}$ & $12.12,4, P=0.017$ \\
\hline $\begin{array}{l}\text { Smoking: Never } \\
\text { Former } \\
\text { Current }\end{array}$ & $\begin{array}{l}0.0486(<0.0030,0.263) \\
0.0105(-0.0209,0.0958) \\
0.110(-0.0107,0.463)\end{array}$ & $1.543,2, P=0.46$ \\
\hline $\begin{array}{l}\text { Benzene: Unexposed } \\
\quad>0-200 \\
>200\end{array}$ & $\begin{array}{l}0.0151(<-0.0056,0.105) \\
-0.0267(\mathrm{NC}, \mathrm{NC}) \\
0.166(0.0100,>0.394)\end{array}$ & $4.886,2, P=0.087$ \\
\hline $\begin{array}{l}\text { Benzene, adjusted for sex: Unexposed } \\
\quad>0-200 \\
>200\end{array}$ & $\begin{array}{l}0.00439(<-0.0102,>0.0284) \\
-0.0267(\mathrm{NC}, \mathrm{NC}) \\
0.147(<0.0413,0.252)\end{array}$ & $5.116,2, P=0.078$ \\
\hline
\end{tabular}

Notes. All models are age-adjusted (through incidence density sampling). Models adjust for other factors as indicated in the first column.

${ }^{a}$ Confidence interval not calculable because point estimate is on the boundary defined by $-1 / \max$ dose [ref. (27), p. 56].

linear model are $3.15 \%$ (95\% CI: $1.58 \%$ to $5.67 \%$ ) per 10 mGy. The doses observed in this study are in a range predicted to be dominated by the linear component of the linear-quadratic model. However, the negative quadratic coefficient estimate and the increase in risk per unit dose ob-

TABLE 6

Risk Estimates for Non-CLL Leukemia (excluding 22 of uncertain type) Related to Cumulative 2Year-Lagged Equivalent Dose to Bone Marrow from Photons, Tritium, Neutrons and Plutonium

\begin{tabular}{ll}
\hline \multicolumn{1}{c}{ Dose category } & \multicolumn{1}{c}{ OR (likelihood-based } \\
$95 \% \mathrm{CI})$
\end{tabular}

Notes. All models are age-adjusted (through incidence density sampling). Models adjust for other factors as indicated. served when analyses were restricted to cumulative doses lower than $100 \mathrm{mSv}$ suggest that there may be attenuation of risk per unit dose at high doses. This phenomenon, frequently observed in other studies of occupational carcino-

TABLE 7

Risk Estimates for Non-CLL Leukemia $(n=187)$ Related to Cumulative Two-Year-Lagged Equivalent Dose to Bone Marrow from Photons, Tritium, Neutrons and Plutonium, Excluding Workers who Received $\geq \mathbf{1 0 0} \mathbf{m S v}$ Cumulative External Dose

\begin{tabular}{ll}
\hline \multicolumn{1}{c}{ Dose category } & \multicolumn{1}{c}{ OR (likelihood-based } \\
$95 \% \mathrm{CI})$
\end{tabular}

Notes. All models adjusted for age (through incidence density sampling). Models adjust for other factors as indicated. 
TABLE 8

Effect of Lag Adjustments on Excess Relative Risk of Non-CLL Leukemia for Total Bone Marrow Dose (including Plutonium)

\begin{tabular}{|c|c|c|c|c|}
\hline \multirow[b]{2}{*}{ Lag } & \multicolumn{2}{|c|}{ Including all workers } & \multicolumn{2}{|c|}{ Birth year $>1921$ only } \\
\hline & Model deviance & $\mathrm{ERR} \cdot 10 \mathrm{mSv}^{-1}(95 \% \mathrm{CI})$ & Model deviance & $\mathrm{ERR} \cdot 10 \mathrm{mSv}^{-1}(95 \% \mathrm{CI})$ \\
\hline \multicolumn{5}{|l|}{ Unadjusted: } \\
\hline 0 years & 659.943 & $0.0385(-0.0052,0.118)$ & 128.437 & $0.59(0.13,2.4)$ \\
\hline 2 years & 659.814 & $0.0403(-0.00469,0.122)$ & 128.658 & $0.55(0.13,2.1)$ \\
\hline 5 years & 660.037 & $0.0394(-0.00586,0.123)$ & 128.673 & $0.60(0.14,2.4)$ \\
\hline 7 years & 660.317 & $0.0372(-0.00729,0.121)$ & 128.417 & $0.68(0.15,3.1)$ \\
\hline 10 years & 662.642 & $0.0290(-0.00103,0.106)$ & 130.397 & $0.58(0.12,2.5)$ \\
\hline \multicolumn{5}{|c|}{ Sex-adjusted: } \\
\hline 0 years & 650.227 & $0.0229(<-0.0103,0.0902)$ & 128.310 & $0.53(0.099,2.5)$ \\
\hline 2 years & 650.130 & $0.0243(<-0.0103,0.0937)$ & 128.518 & $0.50(0.095,2.2)$ \\
\hline 5 years & 650.252 & $0.0235(<-0.0102,0.0943)$ & 128.538 & $0.54(0.10,2.5)$ \\
\hline 7 years & 650.398 & $0.0219(<-0.0102,0.0928)$ & 128.304 & $0.61(0.11,3.2)$ \\
\hline 10 years & 650.806 & $0.0160(<-0.0102,0.0811)$ & 130.197 & $0.51(0.082,2.4)$ \\
\hline
\end{tabular}

Notes. All models adjusted for age (through incidence density sampling). Other factors are adjusted in model as indicated.

gens (30), has been attributed to the healthy worker survivor effect (HWSE), exposure misclassification that is greater for workers receiving high as compared to low exposures, confounding by other risk factors, or saturation of enzyme-mediated carcinogenic pathways (30-32). However, the HWSE is unlikely to explain attenuation for cancers like leukemia that are not strongly related to lifestyle factors $(30)$.

A recent study of residential radon-exposed populations observed attenuation of risk in the highest dose group (33) and suggest that it is due to dose skewness. Recommendations based on simulations include the use of trimmed dose values (e.g., excluding study subjects within the top $1 \%$ of the dose distribution) (29). A comparison of the predicted relative risks using a variety of dose-response coefficients with the observed categorical results (Fig. 1) suggests that risk is underpredicted over most of the informative dose range within the study with all models except a trimmed (1\%) linear-quadratic ERR model.

The results of varying the dose lag suggest that latencies are quite short for non-CLL leukemia; the best fit was provided for lags of 2 years in most situations. Workers born earlier had peak risks observed in the 5-20-year period, while workers born later showed highest risks between 0 and 2 years and again between 5 and 20 years.

Workers born later showed higher radiation-associated risk than workers in earlier birth cohorts. Workers hired later also had higher radiation risk than early workers. These findings are heavily influenced by the highest-exposed workers in the study, since the birth cohort and hire year radiation effect modification disappeared when excluding workers with doses above $100 \mathrm{mSv}$. Possible reasons for this include (1) exposure overestimation among monitored workers and/or unmonitored dose among putatively low-dose workers in the early years of nuclear facility operation, (2) case underascertainment during the early years of follow-up, when doses were generally higher, and (3) exposure underestimation among workers in the later years of nuclear facility operation. The third explanation is not likely, since it is assumed that monitoring techniques and coverage became more accurate over time.

Underascertainment during the early years of the facilities may have been an issue, because the mechanisms for identifying deaths were generally poor during the 1940s

TABLE 9

Analysis of Radiation-Related Risk of Non-CLL Leukemia by Windows of Years before the Cutoff Date (Age at Death of the Matched Case)

\begin{tabular}{cccc}
\hline $\begin{array}{c}\text { Time window } \\
\text { category }\end{array}$ & $\begin{array}{c}\text { ERR } \cdot 10 \mathrm{mSv}^{-1} \\
(95 \% \mathrm{CI})\end{array}$ & $\begin{array}{c}\text { ERR } 10 \mathrm{mSv}^{-1}(95 \% \mathrm{CI}), \\
\text { birth year } \leq 1921\end{array}$ & $\begin{array}{c}\text { ERR } 10 \mathrm{mSv}^{-1}(95 \% \mathrm{CI}), \\
\text { birth year }>1921\end{array}$ \\
\hline $0-<2$ years & $-0.201(<0,0.624)$ & $-0.299\left(<0, \mathrm{NC}^{a}\right)$ & $2.3(<0,25)$ \\
$2-<5$ years & $-0.186(<0,0.966)$ & $-0.356(<0, \mathrm{NC})$ & $-0.64(<0, \mathrm{NC})$ \\
$5-<10$ years & $0.328(<0, \mathrm{NC})$ & $0.281(<0.279, \mathrm{NC})$ & $1.0(-5.7,5.7)$ \\
$10-<20$ years & $0.164(<0.117,0.424)$ & $-0.0016(<0, \mathrm{NC})$ & $0.74(-1.0, \mathrm{NC})$ \\
$\geq 20$ years & $-0.0241(<0, \mathrm{NC})$ & 0 (Fixed) & $0.24(-0.045, \mathrm{NC})$ \\
\hline
\end{tabular}

Note. Models adjusted for age (through incidence density sampling) and sex.

${ }^{a} \mathrm{NC}$ : not calculable. 


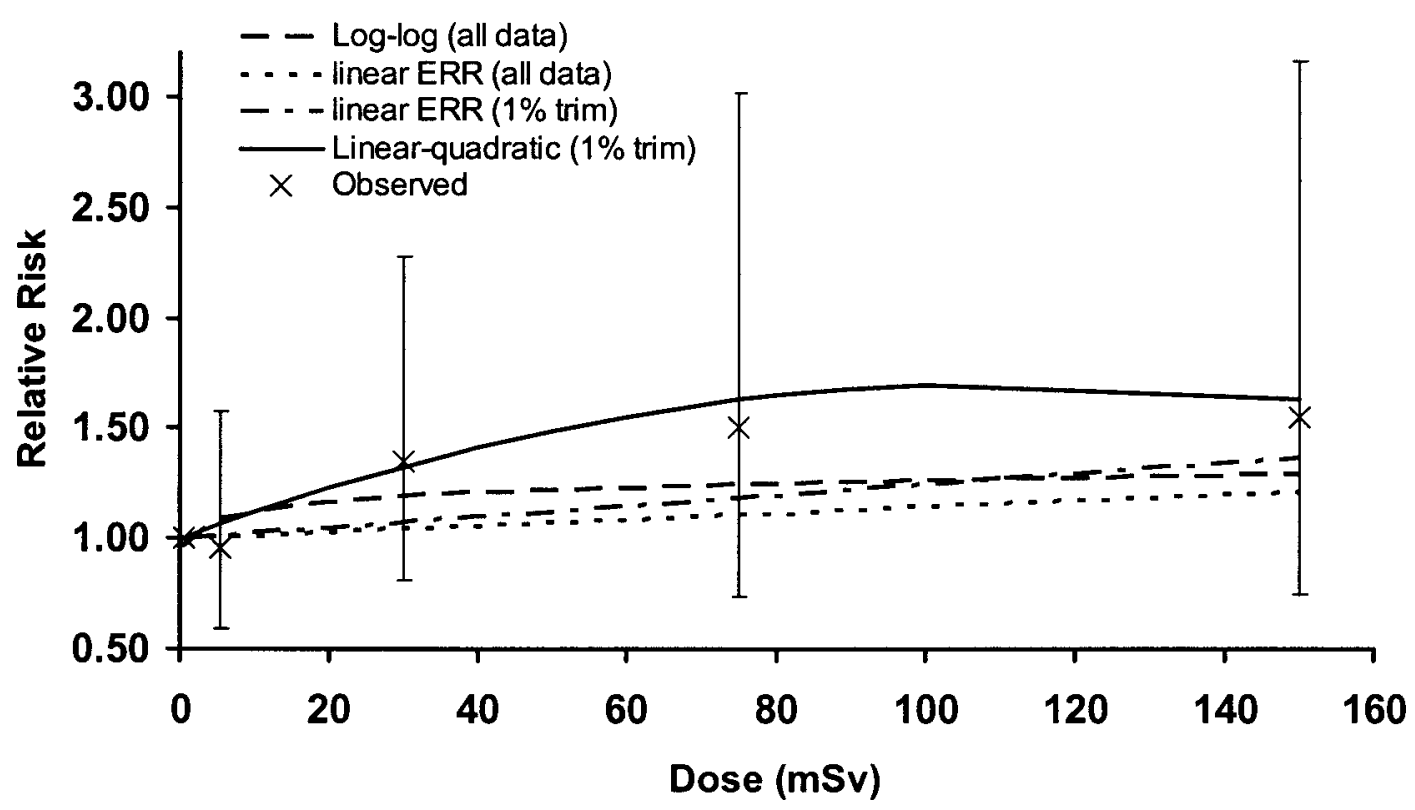

FIG. 1. Comparison of categorical results to various dose-response coefficients (dose in highest category is assigned a value of $150 \mathrm{mSv}$ ). $95 \%$ confidence intervals are shown on the categorical estimates.

and 1950s. Missed internal and external dose during the early years of operation is a possibility. Detection levels for plutonium were relatively high during the 1940s (22), and monitoring did not occur for all potentially exposed workers. Although worker entry into the study required at least one badge monitoring measurement, not every worker was monitored continuously. Monitoring frequency was most complete at ORNL, PNS and SRS and was least complete at LANL, especially among Zia workers during the early years. Some quantitative dosimetry information for LANL workers, not present in the dosimetry records, was found in medical records archived at the site, but not all workers had available medical records. The influence of excluding leukemias of ambiguous type also points to possible exposure misclassification: Most of these cases occurred during early periods of the study, when exposures are most uncertain.

Workers who experienced both elevated benzene exposure scores and high ionizing radiation exposure are of particular interest in this study because of the contribution of both to increased leukemia risk. Assuming no departure from rate-ratio multiplicativity, workers who received 100 $\mathrm{mSv}$ of radiation exposure and the highest benzene exposure scores (thought to be equivalent to more than $200 \mathrm{~h}$ worked at a level equal to or higher than the current benzene exposure limit) experienced a risk 1.92 times (95\% CI: 1.11, 3.30) that of an unexposed worker from the loglinear model (or 2.27 times that of an unexposed worker from the linear ERR model), based on a model that adjusts for sex and excludes leukemias of ambiguous type.

Strengths of the present study include its large size, the inclusion of women, non-white and Hispanic workers, and the characterization of exposures to potential confounders.
The exposure assessment for ionizing radiation in this casecontrol study was improved by the ability to use original records, supplemented with process information for neutron and X-ray dose estimation. Dose estimates used in this study were also adjusted for suspected sources of bias in radiation dosimetry measurement data, in a similar manner as for the IARC 15-country study. Limitations of the study include its generally low power to detect small risks and effect modification and the highly skewed dose distribution.

Most known risk factors for non-CLL leukemia were included in this study; however, the exposure monitoring data for benzene was inadequate to perform a quantitative exposure assessment.

Direct information on smoking was also incomplete for the study subjects; improvements in estimation techniques for missing data may have been possible through the use of multiple imputation or E-M algorithm estimation. However, this limitation is probably minor, since smoking was not strongly associated with either leukemia or dose in this study for workers with non-imputed smoking data, and very few studies have evaluated smoking as a confounder for ionizing radiation and leukemia.

The choice of radiation weighting factor is of course arbitrary; in this study, a range of possible values for neutrons and plutonium was employed, ranging from unity to the standard ICRP 60 values, and including central estimates from a recent comprehensive review of the topic (34) (e.g., 4.1 for plutonium). As a practical matter, the choice of weighting factor for both neutrons and plutonium made little difference to the findings of this study, most likely because these comprised a very small component of the total bone marrow dose. 


\section{CONCLUSION}

This study, one of the largest to evaluate specifically the risk of leukemia among radiation-exposed workers, found overall risk estimates per unit dose to be similar to those found in other studies of nuclear workers and from highdose populations. However, quantitative leukemia risk estimates per unit of radiation dose varied by birth cohort, by year of hire, and with the exclusion of high-dose workers and leukemias of ambiguous type. Several of these factors are highly intercorrelated, making identification of the key effect modifiers difficult. Further studies of this cohort should evaluate patterns of risk among the most recent birth cohort, or more recently hired workers, and should expand the cohort to include workers with more recent exposures. Combination of this cohort with other U.S. nuclear workers with well-characterized, primarily external radiation exposure such as Idaho National Laboratory workers ${ }^{5}$ and nuclear power plant workers (7) could provide clarification of several of these findings. These represent more recent birth cohorts and radiation exposures, and their combination with the later birth cohort or hire dates in the present study should lead to better risk estimation due to the lessened potential for confounding by solvent exposure and increased potential for accuracy in radiation dose assessment.

${ }^{5}$ M. K. Schubauer-Berigan, G. V. Macievic, D. T. Utterback, C-Y. Tseng, An Epidemiologic Study of Mortality and Radiation-Related Risk of Cancer Among Workers at the Idaho National Engineering and Environmental Laboratory, a U.S. Department of Energy Facility. National Institute for Occupational Safety and Health; Health and Human Services (NIOSH) Publication No. 2005-131. Jan 2005. 220 pp. Available by contacting lead author.

APPENDIX TABLE

Example of Cumulative Score Calculation for a Study Subject Exposed to Carbon Tetrachloride

\begin{tabular}{llllcccc}
\hline Agent & Year & Job title & Activity & $\begin{array}{c}\text { Worker } \\
\text { category }\end{array}$ & $\begin{array}{c}\text { Assigned } \\
\text { exposure } \\
\text { level }\end{array}$ & $\begin{array}{c}\text { Duration } \\
\text { (h/day) }\end{array}$ & $\begin{array}{c}\text { Frequency } \\
\text { (days/year) }\end{array}$ \\
\hline $\mathrm{CCl}_{4}$ & 1964 & Operator & Extraction & Performer & 0.1 & 8 & 250 \\
$\mathrm{CCl}_{4}$ & 1965 & Operator & Extraction & Performer & 0.1 & 8 & 200 \\
$\mathrm{CCl}_{4}$ & 1966 & Operator & Extraction & Performer & 0.1 & 8 & 250 \\
$\mathrm{CCl}_{4}$ & Cumulative & & & & & 250 & 200 \\
\hline
\end{tabular}

${ }^{a}$ The chemical exposure score has no units and was calculated using the assigned exposure level (no units), the duration in hours per day, and the frequency in days per year.

\section{ACKNOWLEDGMENTS}

Funding for this study was provided by the U.S. Department of Energy through an agreement with the U.S. Department of Health and Human Services. We thank previous investigators for providing access to source data and M. Lawn, G. Petersen and H. Stockwell of DOE for assistance in gaining access to records to conduct this study. L. Hartle and T. Taulbee of NIOSH and R. Anderson, A. Fidler, J. Flora, S. Foster, A. Herrman, R. Hornung, D. Reeder, M. Tolson and T. Wenzl, all formerly at NIOSH, assisted in epidemiological, statistical and exposure issues during the early phases of the study. Assistance with vital status and death certificate ascertainment was provided by Oak Ridge Associated Universities. Many individuals at the DOE and U.S. Navy sites in the study assisted by providing access to records and data needed for the study, in particular J. Brann, K. Crase, E. Dixon, J. Fix, T. LaBone, J. McClellan, R. Meade, G. Miller, R. Morgan, D. Quintanna, J. Voltin, P. Wallace and L. Wiggs. The findings and conclusions in this report are those of the authors and do not necessarily represent the views of the National Institute for Occupational Safety and Health.

Received: June 19, 2006; accepted: September 18, 2006

\section{REFERENCES}

1. M. K. Schubauer-Berigan and T. W. Wenzl, Leukemia mortality among radiation-exposed workers. Occup. Med. State Art Rev. 16, 271-287 (2001).

2. E. Ron, Cancer risks from medical radiation. Health Phys. 85, 4759 (2003).

3. D. L. Preston, D. A. Pierce, Y. Shimizu, H. M. Cullings, S. Fujita, S. Funamoto and K. Kodama, Effect of recent changes in atomic bomb survivor dosimetry on cancer mortality risk estimates. Radiat. Res. 162, 377-389 (2004).

4. L. Y. Krestinina, D. L. Preston, E. V. Ostroumova, M. O. Degteva, E. Ron, O. V. Vyushkova, N. V. Startsev, M. M. Kossenko and A. V. Akleyev, Protracted radiation exposure and cancer mortality in the Techa River Cohort. Radiat. Res. 164, 602-611 (2005).

5. National Research Council, Committee to Assess Health Risks from Exposure to Low Levels of Ionizing Radiation, Health Risks From Exposure to Low Levels of Ionizing Radiation. BEIR VII Phase 2. National Academies Press, Washington, DC, 2005.

6. C. R. Muirhead, A. A. Goodill, R. G. Haylock, J. Vokes, M. P. Little, D. A. Jackson, J. A. O'Hagan, J. M. Thomas, G. M. Kendall and G. L. Berridge, Occupational radiation exposures and mortality: second analysis of the National Registry for Radiation Workers. J. Radiol. Prot. 19, 3-26 (1999).

7. G. R. Howe, L. B. Zablotska, J. J. Fix, J. Egel and J. Buchanan, Analysis of the mortality experience amongst U.S. nuclear power industry workers after chronic low-dose exposure to ionizing radiation. Radiat. Res. 162, 517-526 (2004).

8. T. L. Kubale, R. D. Daniels, J. H. Yiin, J. Couch, M. K. SchubauerBerigan, G. M. Kinnes, S. R. Silver, S. J. Nowlin and P. H. Chen, A nested case-control study of leukemia mortality and ionizing radiation at the Portsmouth Naval Shipyard. Radiat. Res. 164, 810-819 (2005).

9. E. Cardis, M. Vrijheid, M. Blettner, E. Gilbert, M. Hakama, C. Hill, G. Howe, J. Kaldor, C. R. Muirhead and K. Veress, Risk of cancer after low doses of ionising radiation: retrospective cohort study in 15 countries. Br. Med. J. 331, 77 (2005).

10. E. S. Gilbert, D. L. Cragle and L. D. Wiggs, Updated analyses of combined mortality data for workers at the Hanford Site, Oak Ridge National Laboratory, and Rocky Flats Weapons Plant. Radiat. Res. 36, 408-421 (1993).

11. E. L. Frome, D. L. Cragle, J. P. Watkins, S. Wing, C. M. Shy, W. G. 
Tankersley and C. M. West, A mortality study of employees of the nuclear industry in Oak Ridge, Tennessee. Radiat. Res. 148, 64-80 (1997).

12. D. L. Cragle, J. P. Watkins and K. Robertson-Demers, Mortality among workers at the Savannah River nuclear fuels production facility. In 1998 Proceedings of the Section on Statistics in Epidemiology, pp. 83-87. American Statistical Association, Alexandria, VA, 1999.

13. L. D. Wiggs, E. R. Johnson, C. A. Cox-Devore and G. L. Voelz, Mortality through 1990 among white male workers at the Los Alamos National Laboratory: considering exposures to plutonium and external ionizing radiation. Health Phys. 67, 577-588 (1994).

14. R. A. Rinsky, R. D. Zumwalde, R. J. Waxweiler, W. E. Murray, Jr., P. L. Bierbaum, P. J. Landrigan, M. Terpilak and C. Cox, Cancer mortality at a naval nuclear shipyard. Lancet 1, 231-235 (1981).

15. J. J. Beaumont, K. Steenland, A. Minton and S. Meyer, A computer program for incidence density sampling of controls in case-control studies nested within occupational cohort studies. Am. J. Epidemiol. 129, 212-219 (1989).

16. H. Checkoway, N. Pearce and D. Kriebel, Research Methods in Occupational Epidemiology, 2nd ed. Oxford University Press, Oxford, 2004.

17. R. D. Daniels and M. K. Schubauer-Berigan, Bias and uncertainty of penetrating photon dose measured by film dosemeters in an epidemiological study of US nuclear workers. Radiat. Prot. Dosim. 113, 275-289 (2005).

18. R. D. Daniels, T. D. Taulbee and P. Chen, Radiation exposure assessment for Portsmouth Naval Shipyard health studies. Radiat. Prot. Dosim. 111, 139-150 (2004).

19. R. D. Daniels and J. H. Yiin, A comparison of statistical methods for estimation of less than detectable ionising radiation exposures. Radiat. Prot. Dosim., in press. [10.1093/rpd/ncl024]

20. A. Servomaa and M. Tapiovaara, Organ dose calculations in medical X-ray examinations by the program PCXMC. Radiat. Prot. Dosim. 80, 213-219 (1998).

21. J. L. Anderson and R. D. Daniels, Bone marrow dose estimates from work-related medical x-ray examinations given between 1943 and 1966 for personnel from five U.S. nuclear facilities. Health Phys. 90 , 544-553 (2006).

22. R. D. Daniels, C. Lodwick, M. K. Schubauer-Berigan and H. Spitz, Assessment of plutonium exposures for an epidemiologic study of US nuclear workers. Radiat. Prot. Dosim. 118, 43-55 (2005).
23. ICRP, 1990 Recommendations of the International Commission on Radiological Protection. Publication 60, Annals of the ICRP, Vol. 21, Elsevier, Amsterdam, 1991.

24. Threshold Limit Values for Chemical Substances and Physical Agents and Biological Exposure Indices. American Conference of Governmental Industrial Hygienists, Cincinnati, OH, 2004.

25. J. H. Yiin, M. K. Schubauer-Berigan, S. R. Silver, R. D. Daniels, G. M. Kinnes, D. D. Zaebst, J. R. Couch, T. L. Kubale and P-H. Chen, Risk of lung cancer and leukemia from exposure to ionizing radiation and potential confounders among workers at the Portsmouth Naval Shipyard. Radiat. Res. 163, 603-613 (2005).

26. U.S. Department of Health and Human Services, Mortality Risks by Occupation among U.S. Veterans of Known Smoking Status 19541980, Vol. 1. NIH Publication No. 92-3407, U.S. Department of Health and Human Services, Washington, DC, 1992.

27. D. L. Preston, J. H. Lubin, D. A. Pierce and M. E. McConney, Epicure User's Guide. Hirosoft International Corporation, Seattle, 1993.

28. National Research Council, Committee on the Biological Effects of Ionizing Radiation, Health Effects of Exposure to Low Levels of Ionizing Radiation (BEIR V). National Academy Press, Washington, DC, 1990.

29. A. S. Rosario, J. Wellman, I. M. Heid and H-E. Wichmann, Radon epidemiology: continuous and categorical trend estimators when the exposure distribution is skewed and outliers may be present. J. Toxicol. Environ. Health A 69, 681-700 (2006).

30. L. Stayner, K. Steenland, M. Dosemeci and I. Hertz-Piccioto, Attenuation of exposure-response curves in occupational cohort studies at high exposure levels. Scand. J. Work Environ. Health 29, 317-324 (2003).

31. I. Hertz-Picciotto and A. H. Smith, Observations on the dose-response curve for arsenic exposure and lung cancer. Scand. J. Work Environ. Health 19, 217-226 (1993).

32. H. Kromhout and D. Heederik, Occupational epidemiology in the rubber industry: implications of exposure variability. Am. J. Indust. Med. 27, 171-185 (1995).

33. L. Kreienbrock, M. Kreuzer, M. Gerken, G. Dingerkus, J. Wellmann, G. Keller and H. E. Wichmann, Case-control study on lung cancer and residential radon in Western Germany. Am. J. Epidemiol. 153, 42-52 (2001).

34. D. C. Kocher, A. I. Apostoaei and F. O. Hoffmann, Radiation effectiveness factors for use in calculating probability of causation of radiogenic cancers. Health Phys. 89, 3-32 (2005). 